Semina $\square \quad \mathrm{Nr} 16$

Scientiarum 2017

s. $155-167$

DOI: http://dx.doi.org/10.15633/ss.2489

Marek Jakubiec, Bartosz Janik ${ }^{1}$

\title{
Folk Psychology and Law: the Case of Eliminativism
}

"If commonsense psychology were to collapse, that would be, beyond comparison, the greatest intellectual catastrophe in the history of our species." 2

It is a truism that we all have a certain image of world, which not always is coherent with the scientific one. It can be called the 'folk' image. The difference between the manifest and scientific images, as Sellars ${ }^{3}$ puts it in other words, may be significant. In almost every part of contemporary science the distinction between those two emerges. As a consequence, the disparities between scientific and folk conceptual frameworks appear. This issue is truly relevant from the legal perspective. Legal conceptual frameworks (which constitute the 'legal image of world') determine the content of legal norms. This image bears a certain relation to the 'folk psychological image of the world'. It might be said, in great simplifica-

1 Marek Jakubiec is funded from Polish National Centre, grant no. DEC-2012/04/A/HS5/00655. Bartosz Janik is funded from Polish National Centre, grant no. 2016/23/N/HS5/00952. This paper was written within the research project 'Law $\&$ Neuroscience. A New Paradigm in the Philosophy of Law' sponsored by the Foundation for Polish Science.

2 J. Fodor, Psychosemantics, Cambridge 1987, p. xii.

3 W. Sellars, Philosophy and the Scientific Image of Man, in: Frontiers of Science and Philosophy, ed. R. Colodny, Pittsburgh 1962, p. 35-78. 
tion of the matter, that the naturalization of the discussed domain seeks to establish a correct relation between the scientific and folk images of the given domain and supplies a method to reduce the folk image to the scientific image. ${ }^{4}$ Our point here will be that this is not always possible.

What is the legal image of world? Although law is of normative (prescriptive) character, normative statements cannot be formulated without certain descriptive presuppositions. The content of legal system (understood as a set of various legal norms) is dependent on the certain image of world: the legal image.

The particularly relevant element of the folk image is folk psychology. There are many concepts - like beliefs, desires, intentions - which at the present moment are simply not translatable into the scientific ones. The relation between the folk and scientific images (or conceptual schemes) can be described in various ways but only a handful of them might be interesting for the legal sciences in light of the naturalization. In this article we will consider dependence as a possible relation between the legal and folk domains to conclude that one possible way out of this picture (elimination) is in fact not a viable option for legal scholars. We will argue briefly that, in order to succeed at modelling it in a coherent way, one has to postulate a more relaxed account of the abovementioned relation. An important thing to note is that for the radical naturalization, there exists a second viable solution, i.e. the reduction of folk psychological terms to legal (broadly conceived as conjunction of legal and descriptive) terms. As reductionists, we could argue that if folk psychological terms cannot be eliminated from the given discourse, then maybe we could provide a way to reduce them to more basic terms (preferably neuroscientific). This venture is similar to the general problem of reductionism in philosophy of mind and we could argue from the philosophical account that this project is not a viable option because of the some well-known general problems.

4 In the case of law, one might argue that we have legal image, scientific image, and folk image altogether. For the sake of the argument, we assume that we have no problem with enriching the legal image with scientific knowledge. 
For example, there is a problem with precise definition of folk terms and one might argue that this is not only a practical issue but also a theoretical issue. The theoretical issue stems from the fact that in order to provide precise definition term in question should refer to natural kind. In case of folk psychology, there are very good arguments that folk terms do not refer to natural kinds because our best theories of how psychological terms refer assume shallow criteria of application. ${ }^{5}$ For the sake of simplicity, we are putting the reductionist option aside and focus on eliminativism.

Back to the main problem of this paper, the issue we analyze can be also expressed as the problem of the limits of naturalism in the context of law and of the significance of neuroscience (as scientific image of the world) for law.

Our aim in this paper is to demonstrate that radical naturalization with classical elimination of the terms is impossible between legal and scientific discourse due to the general philosophical problems with eliminativism. In our opinion, the analysis of relation between folk psychology and law in the context of the naturalization of jurisprudence unveils the limits of general tendency to the replacement approach concerning different conceptual schemes, not merely in the case of folk and scientific. It is also linked - in a specific way - to the issue of useful fictions in law. ${ }^{6}$ Folk psychology - even if falsified - is a necessary element of the conceptual system of law and cannot be replaced by other kind terms, e.g. scientific. The second and third parts serve as philosophical preliminaries and fourth is a signalization of our proposal.

What is to be stressed, our paper is rather exploratory than a typical research paper, hence we focus on elucidation of the problem. In our opinion it is of great relevance for both general philosophy

5 See for example E. Schwitzgebel, A Dispositional Approach to Attitudes: Thinking outside of the Belief Box, "New Essays on Belief" (2013), p. 75-99.

6 We are also not covering the fictionalist account of legal discourse. For more information see for example D. Gawthorne, Fictionalising Jurisprudence: An Introduction to Strong Legal Fictionalism, "Australian Journal of Legal Philosophy" 38 (2013), p. 52-73. 
and theory of law. The theoretical solutions of the problem may be important for the future practice of lawmaking.

The abovementioned issues have been already (but relatively rarely) analyzed by the legal philosophers. For instance, Katrina Sifferd defend the use of commonsense psychology (we use this term and "folk psychology" interchangeably) in law, especially in the context of criminal proceedings. Folk concepts seem to be a kind of necessary condition of understanding the responsibility. This is because of the ascription of responsibility lies on our mindreading abilities. As she remarks:

(...) if CSP [commonsense psychology - M. J., B. J.] is a poor or inaccurate theory of what other people have going on in their heads, the criminal law, which specifically uses a commonsense psychological approach to classify criminal defendants, may consequently be doing a poor job of determining who is guilty of a crime. ${ }^{7}$

We agree with this argument in principle, but not completely. Our opinion is folk psychology seems to be rather "immune" in this context, even if it is merely a useful fiction.

\section{What is folk psychology?}

Folk psychology can be simply described as a theory of mental states. $^{8}$ As a theory, folk psychology is used as a guide to mental state ascription, as a predictive tool for behavior of subjects to whom mental states are ascribed to, and as a guide for construction of explanation of behavior of mentioned subjects. We will deal with this meaning of the term folk psychology. In contemporary philosophical literature there are several ongoing debates concerning folk psy-

7 K. Sifferd, Psychology and the Criminal Law, London 2004, p. 576.

8 See S. Stich, I. Ravenscroft, What Is Folk Psychology?, “Cognition” 50.1 (1994), p. 447 . 
chology. ${ }^{9}$ Short review of those debates will serve as a guide to different concepts used by the debaters. First, there is a debate going concerning the correct approach to folk psychology. On the one hand we have the theory-theory approach which can be summarized as perceiving a folk psychology as a mental theory of human behavior represented in our brains. ${ }^{10}$ From the cognitive point of view this is a mindreading approach because cognitive ability underlying folk psychology is mindreading. There is also a platitude approach to folk psychology connected with work of David Lewis. ${ }^{11}$ Lewis argues that correct approach to folk psychology is an approach endorsing so-called platitudes which are simply commonsense sentences about our mental states. Those sentences as a whole introduce theoretical terms to our folk theory of mental states thus forming notions like belief and desire which are focal to folk psychology. Platitudes are generated by the studied population and the problem of collecting and generating platitudes is independent from the issue of correct cognitive ability underlying folk psychology. Last one is a mental simulation approach to folk psychology which endorses the role of simulation. ${ }^{12}$ Adherents of this approach underline the need to imagine the other person's attitude towards something rather than the need to attribute beliefs and desires to her.

Secondly, there is an ongoing debate concerning the status of folk psychology as a scientific theory. ${ }^{13}$ To confirm the scientific status of folk psychology one need to ask whether it proposes some sort of scientific laws, whether objects studied by it are genuine scientific objects (elaborate) and whether there are methods of verification to claims formulated by it. The issue is important in contemporary phi-

9 For overview, see I. Ravenscroft, Folk Psychology as a Theory, in: The Stanford Encyclopedia of Philosophy, ed. E. N. Zalta, https://plato.stanford.edu/archives/ fall2016/entries/folkpsych-theory (22.11.2017).

10 See J. Fodor, The Language of Thought, vol. 5, Cambridge 1975.

11 See D. Lewis, Reduction of Mind, in: A Companion to Philosophy of Mind, ed. S. Guttenplan, Oxford 1966, p. 412-431.

12 See R. M. Gordon, Folk Psychology as Simulation, "Mind \& Language" 1 (1986) no. 2 , p. $158-171$.

13 See S. Stich, From Folk Psychology to Cognitive Science: The Case against Belief, Cambridge 1983, Ch. 1. 
losophy of mind and in all philosophical inquiries concerning the role of mental states in generating conceptual schemes. The folk psychology as a scientific theory should have proper subject (mental states as some kind of natural kinds), should create scientific generalisations and have objective methods of verification. As we will see, the scientific character of folk psychology ignited a huge debate about a need of its elimination as a bad scientific theory. ${ }^{14}$

\section{Eliminativism and folk-psychology}

In the philosophy of mind and philosophy of psychology there is a huge argument whether objects postulated by the folk psychology should be eliminated, or treated in a different way. The important thing to notice is that the dualistic account of law and folk psychology is obviously not satisfactory for the legal scholars. In case of the dualistic account we will have problem with the providing one narration that will join folk psychology in legal (i.e. evidentiary and normative) context. The problem is even harder when we consider the need for an account of mental causation i.e. for the criminal law compared to the problems with mental causation that dualist has. ${ }^{15}$

Turning back to the eliminativism debate, brief summary of it is simple: one side of the table is arguing that the folk psychology is a bad theory and all objects this theory is posting should be eliminated; the other side is trying to resist. There is a lot of apparently good arguments supporting the claim that folk psychology is a bad theory. (All other folk theories are considered as bad theories (folk physics, folk biology), there are no good folk generalizations, and so on. $)^{16}$ The central notion in the eliminativism debate is the no-

14 See S. Stich, From Folk Psychology..., op. cit.

15 See K. Sifferd, Psychology and the Criminal Law, op. cit. See also: J. Kim, Mind in a Physical World: An Essay on the Mind-Body Problem and Mental Causation, Cambridge 2000.

16 Arguments endorsed by Stich and Churchland. See S. Stich, From Folk Psychology..., op. cit.; P. Churchland, Eliminative Materialism and the Propositional Attitudes, "The Journal of Philosophy" 78.2 (1981), p. 67-90. 
tion of theory. To be precise, philosophical debate about folk psychology is concerned with theoretical terms of this theory which in this case are beliefs, desires and other mental states. ${ }^{17}$ Eliminativism is claiming that those theoretical terms should be eliminated due to general failure of folk psychology as a theory. Before moving to the analysis of the eliminativism debate we should acknowledge distinction between traditional and scientific eliminativism which sometimes is blurred in philosophical analysis of eliminativism. ${ }^{18}$ Traditional eliminativism is the view that term should be eliminated from everyday speech due to its failure to refer. Scientific eliminativism is the view that the term should be eliminated from scientific discourse due to its lack of referential utility. ${ }^{19}$ The point of the difference between those two kinds of eliminativisms is to stress that there are different criteria of elimination connected strongly with the usability for the desired discourse. ${ }^{20}$ The usability matter will be of great importance latter. The thing of great importance is that there are different criteria of elimination in both accounts and there is no simple transition between scientific and traditional eliminativism. ${ }^{21}$

Moving to the analysis of the eliminativism debate one should stress that although eliminativism seems very promising for naturalistically oriented approach to a given discourse, the apparently simple and very efficient eliminativist argumentation is relying on strong philosophical assumption. In effect, this assumption makes whole eliminativist enterprise much more difficult. The implicit assumption is the favored theory of reference. Because of that, and with the addition that anti-eliminativists favors different theory of reference, the argument between the eliminativists and their opponents

17 See D. Lewis, How to Define Theoretical Terms, "The Journal of Philosophy" 67.13 (1970), p. 427-446.

18 See J. Corns, Pain Eliminativism: Scientific and Traditional, "Synthese" 193.9 (2016), p. 2949-2971.

19 See E. Machery, Doing without Concepts, Oxford 2009.

20 See J. Corns, Pain Eliminativism..., op. cit., p. 2970.

21 See J. Corns, Pain Eliminativism..., op. cit. 
became the argument over the correct theory of reference. ${ }^{22}$ This latter debate does not have one correct solution and thus the apparent simple and objective criteria of elimination should be dropped. This moves us back to the usage criteria of elimination which now does not look so harsh for every discourse (we can say that in scientific discourse term should be eliminated when it is useless with providing generalizations and in traditional discourse the term is useless when it cannot facilitate successful communication). ${ }^{23}$

To sum up, eliminativism at first glance looks like theory that gives priority to the scientific account of a given reality. It turns out actually that the strong criteria of elimination, suggested by Patricia Churchland and Stephen Stich, are in fact useless and probably only usability criterion should be used as a basis for eliminativism. That suggests that when two discourses collide, there is no simple way to favor one and eliminate other because usability criteria vary from discourse to discourse. What is more, there is no straightforward connection between scientific and traditional eliminativism i.e. the former does not imply the latter.

\section{Why does law need folk psychology?}

In this section we will briefly explore whether eliminativism can be treated as a position concerning the relation between the folk and scientific conceptual frameworks in the context of the descriptive presuppositions of legal norms and the meaning of legal concepts. In section two we briefly presented some arguments for and against eliminativism in a general context of philosophy of mind. Here we will argue why Fodor's objection we quoted at the very beginning matters in legal philosophy.

As we remarked earlier, the statements describing certain aspects of reality are an important part of legal system. As the presuppositions of legal norms they are what we call the 'legal image

22 See S. Stich, From Folk Psychology..., op. cit.

23 See J. Corns, Pain Eliminativism..., op. cit. 
of world' (or the legal conceptual scheme). The sound approximation of this image might be a union of all sentences describing legal content of the legal system and all sentences describing the world relevant from the legal point of view. In the context of naturalization of law an interpretation was proposed based on three types of relation (R) between the scientific knowledge (SK) and the legal knowledge (LK). In the light of 'radical naturalization' it is an equivalence (material) relation between LK and a certain fragment of SK. The adherents of moderate naturalization assert there is a weaker logical relation between these two types of knowledge (for instance supervenience). Eventually, supporters of excluding the very possibility of naturalization would express a position that there is no such relation. ${ }^{24}$ It corresponds to the problem of eliminativism/conservatism concerning the folk psychology we mentioned earlier.

Let us first consider briefly the significance of folk psychology in law. As we emphasized in the second part, it is related to the capacity of 'mindreading'. Obviously without such ability it would not be possible to achieve a certain level of understanding other people's minds. It is a crucial element of criminal proceedings, when the responsibility is ascribed. Without going into the details, one of its prerequisites is the ascertainment of the agent's intent. For instance, the judge is interpreting the behavior of the accused in a certain way and on that basis is using the folk psychological category of intent to use it within legal framework. On the other hand, if someone was unable to foresee the set of possible consequences of his actions, he will not met folk psychological criteria of intent and will not be treated as criminally responsible for his actions. This issue, from the legal theoretical point of view, is much more complicated but here is needed just to justify indispensability of folk psychological concepts within legal framework.

What we presented above is rather a truism. It is how we nor $\mathrm{m}$ ally think our mind works. But according to the scientific knowl-

${ }_{24}$ See B. Brożek, O naturalizacji prawa (On the Naturalization of Law), in: Naturalizm prawniczy. Interpretacje (Legal Naturalism. Interpretations), red. J. Stelmach, B. Brożek, Ł. Kurek, K. Eliasz, Warszawa 2015, p. 26. 
edge the folk psychological criteria of assessment of mental states are not scientific at all and no one should be held responsible for his actions under set on unscientific criteria. So, the problem arises: whether they should be naturalized? If so, under which circumstances?

In our opinion the relation between the folk and legal image is really strong. Even if folk concepts are merely concepts that denote nothing, these are concepts we think by. At the present stage of scientific and philosophical development it is impossible to eliminate the concept of "intent" or "will" from the legal conceptual framework just because the criterion of the elimination should be the usability of the (suspicious) concepts and within legal theoretic framework the concepts such as "intent" are very useful. The interesting question is what is the desired account of usefulness for legal discourse. And it is irrelevant whether this position is acceptable (or even if it will be accepted) in the philosophy of mind. The situation will not differ even if we assume that eliminativism is true. The necessary condition for the elimination is usability which in legal case is strongly connected to social perception of law. To accept eliminativism is to change people's attitudes towards usability of the new concepts deployed: if the majority of society accepts eliminativism it will be justified to modify the law. If people generally endorse folk psychology, merely the 'folk conceptual scheme' is to be the basis for the legal one.

Sifferd's conclusions are similar, as she notices:

(...) if eliminativists are right about CSP the criminal law faces real problems. Eliminativists claim that beliefs and desires are not 'real' psychological entities, and thus as a psychological theory CSP should be abandoned for other explanations of human behavior that postulate real psychological states. ${ }^{25}$

At first glance, the implication in the first sentence may seem to be true. However, in our opinion, even if eliminativists are right

25 K. Sifferd, Psychology and the Criminal Law, op. cit., p. 577. 
in this context, it does not cause real problem for the criminal law (and for law generally). Moreover, as we pointed earlier the philosophical problems eliminativists have to face with are numerous and the folk psychology is not even eliminable in the philosophical discourse. Nonetheless, even if from the perspective of neuroscience and philosophy of mind eliminativism were evaluated as a commonly accepted position, it does not automatically cause problems for legal concepts. Folk psychology will be then rather treated as useful description than replaced by other description of human mental processes and behaviour.

The role of legal constructs, institutions, concepts, etc. obviously is not to describe the reality, but rather to efficiently regulate human behaviour. Certainly it may seem law should be coherent with science. If the descriptive presuppositions of norms are based on archaic ways of understanding the certain elements of reality it will negatively influence the quality of law and make it inadequate. But, as we tried to demonstrate, the issue is more complex it may seem to be prima facie. If there is a tendency among scientists and philosophers to eliminate certain folk concept, it does not imply it should be eliminated from our ordinary speech and legal language. The dichotomy of scientific and traditional eliminativism we pointed earlier seems to be relevant in this context.

\section{Conclusion}

Radical naturalization with classical elimination of the terms is impossible between legal and scientific discourse due to the general philosophical problems with eliminativism. What is more, replacing traditional criteria of elimination by the usability criterion will not suffice for elimination of folk terms from legal image of the world. In other words, scientific eliminativism does not justify traditional eliminativism in the legal realm. This conclusions could serve as an indicator of limits of naturalization in jurisprudence. This point is preliminary in its nature and is generating a lot of additional issues. For example, one could argue that the change of strategy to 
reductionism might suffice for a correct account for folk psychology within legal image of the world. What is more, there is a strong tendency to treat law as useful fiction and whole legal discourse as a case of fictional discourse. This idea need much more elaboration than the length of this paper and as such was put aside. ${ }^{26}$

To conclude, one has to observe that the crucial relation between folk psychology and legal image of the world cannot be straightforwardly modelled as "strong" dependence that allows reduction (or elimination). In order to accurately model this relation, one will have to postulate more relaxed account (for example, supervenience or normative grounding). The problem of naturalization of legal image of the world seems to need more detailed philosophical work.

\section{Summary}

\section{Folk Psychology and Law: the Case of Eliminativism}

The aim of this paper is very modest. First, we want to assess how different strategies of naturalization might deal with the need of using folk psychology in legal domain. Second, we want to check whether folk psychology is indeed indispensable in the legal domain. Third, we want to describe possible problems with one strategy of naturalization, i.e. radical naturalization with classical elimination. Our conclusion will be that despite various attempts, every project of naturalization of law will have to resolve the tension between law and folk psychology and such resolution would not be achieved by simple reduction or elimination of folk psychology. A variety of non-standard solutions might be in place to resolve this tension. We will only outline those strategies here.

Keywords: folk psychology, eliminativism, legal philosophy, philosophy of mind

\section{Bibliography}

Brożek B., O naturalizacji prawa, in: Naturalizm prawniczy. Interpretacje, red. J. Stelmach, B. Brożek, Ł. Kurek, K. Eliasz, Warszawa 2015.

26 See D. Gawthorne, Fictionalising Jurisprudence..., op. cit. and A. Marmor, Law as Authoritative Fiction, "Cornell Legal Studies Research Paper" 17-10 (2017), https://papers.ssrn.com/sol3/papers.cfm?abstract_id=2921943 (28.11.2017). 
Churchland P., Eliminative Materialism and the Propositional Attitudes, "The Journal of Philosophy” 78.2 (1981), p. 67-90.

Corns J., Pain Eliminativism: Scientific and Traditional, "Synthese" 193.9 (2016), p. 2949-2971.

Fodor J., Psychosemantics, Cambridge 1987.

Fodor J., The Language of Thought, vol. 5, Cambridge 1975.

Gawthorne D., Fictionalising Jurisprudence: An Introduction to Strong Legal Fictionalism, "Australian Journal of Legal Philosophy" 38 (2013), p. 52-73.

Gordon R. M., Folk Psychology as Simulation, "Mind \& Language" 1 (1986) no. 2 , p. 158-171.

Kim J., Mind in a Physical World: An Essay on the Mind-Body Problem and Mental Causation, Cambridge 2000.

Lewis D., How to Define Theoretical Terms, "The Journal of Philosophy” 67.13 (1970), p. 427-446.

Lewis D., Reduction of Mind, in: A Companion to Philosophy of Mind, ed. S. Guttenplan, Oxford 1966, p. 412-31.

Machery E., Doing without Concepts, Oxford 2009.

Marmor A., Law as Authoritative Fiction, "Cornell Legal Studies Research Paper" 17-10 (2017), https://papers.ssrn.com/sol3/papers.cfm?abstract_ $\mathrm{id}=2921943(28.11 .2017)$.

Ravenscroft I., Folk Psychology as a Theory, in: The Stanford Encyclopedia of Philosophy, ed. E. N. Zalta, https://plato.stanford.edu/archives/fall2016/ entries/folkpsych-theory (22.11.2017).

Schwitzgebel E., A Dispositional Approach to Attitudes: Thinking outside of the Belief Box, "New Essays on Belief" (2013), p. 75-99.

Sellars W., Philosophy and the Scientific Image of Man, in: Frontiers of Science and Philosophy, ed. R. Colodny, Pittsburgh 1962, p. 35-78.

Sifferd K., Psychology and the Criminal Law, London 2004.

Stich S., From Folk Psychology to Cognitive Science: The Case against Belief, Cambridge 1983.

Stich S., Ravenscroft I., What Is Folk Psychology?, “Cognition” 50.1 (1994), p. 447. 